\title{
Rancang Bangun Mesin Vertical Screw Molding Dengan Penggerak Dinamo Starter Sebagai Pencair Limbah Plastik
}

\section{Vertical Screw Molding Machine Design Plan With Dinamo Starter As A Diluent Plastic Waste}

\author{
Putu Agus Suryantara', K. Rihendra Dantes ${ }^{1}$, I. N. Pasek Nugraha1 \\ 1Program Studi Pendidikan Teknik Mesin, Universitas Pendidikan Ganesha, Singaraja, Indonesia \\ e-mail: aguspanda9696@gmail.com, rihendra-dantes@undiksha.ac.id, \\ paseknugraha@undiksha.ac.id
}

\begin{abstract}
Abstrak
Penelitian ini merupakan penelitian yang bertujuan untuk menghasilkan rancangan mesin vertical screw molding dengan penggerak dinamo starter sebagai pencair limbah plastik sesuai dengan permintaan dan keinginan customer dengan menggunakan metode yaitu, Quality Function Deployement (QFD). Data kelayakan desain dan data kelayakan produk mesin vertical screw molding didapatkan dari hasil penyebaran angket. Kelayakan rancang bangun mesin vertical screw molding dengan penggerak dinamo starter sebagai pencair limbah plastik melalui beberapa tahap pengembilan data uji angket melalui uji ahli manufaktur, kelompok kecil, dan kelompok besar. Pada uji manufaktur diuji oleh Dosen Pendidikan Teknik Mesin Universitas Pendidikan Ganesha, dan Guru SMK 3 Singaraja dengan mendapakan hasil sangat layak. Pada pengujiian kelompok kecil yang menyasar lima mahasiswa pendidikan teknik mesin, mendapatkan hasil $95,00 \%$ dan dinyatakan sangat layak. Selanjutnya penyebaran angket kelompok besar dengan menyasar mahasiswa dan masyarakat mendapatkan hasil sebesar 90,32\%, dapat dinyatakan bahwa rancangan ini sagat layak. Jadi, berdasarkan hasil penyebaran angket maka rancangan mesin vertical screw molding sangat layak untuk di terapkan.
\end{abstract}

Kata kunci : Limbah Plastik, Mesin Vertical Screw Molding, Quality Function Deployment

\section{Abstract}

This study is a study that aims to produce a vertical screw molding machine design with dynamo starter as a diluent plastic waste in accordance with customer requests and desires using Quality Function Deployement (QFD) method. The design and product feasibility data of the vertical screw molding machine were obtained from the results of questionnaire distribution. The design feasibility of vertical screw molding machine with dynamo starter as a diluent plastic waste were get through several stages of questionnaire test data retrieval through the test of manufacturing experts, 
Jurnal Pendidikan Teknik Mesin Undiksha

Vol. 8 No.1, Maret 2020

p-ISSN: 2614-1876, e-ISSN: 2614-1884

small groups, and large groups. The manufacturing test was tested by the Mechanical Engineering Education Lecturer at Ganesha University of Education, and Singaraja Number 3 Vocational School teachers with very feasible results. In the small group testing which targeted five students of mechanical engineering education, the result was $95.00 \%$ and were declared very feasible. Furthermore, the distribution of large group questionnaires which targeted students and community received $90.32 \%$ results, it can be stated that this design was very feasible. So, based on the results of questionnaire distribution, the design of vertical screw molding machines is very feasible to be applied.

\section{Keywords: Plastic Waste, Vertical Screw Molding Machine, Quality Function Deployment}

\section{PENDAHULUAN}

Pada kehidupan kita sehari dimanapun kita berada limbah plastik adalah kata-kata yang tidak asing bahkan banyak kita sering jumpai di jalan banyak orang tidak peduli terhadap lingkungannya sehingga sering kali mereka membuang sampah-sampah plastik tersebut secara sembarangan mereka tidak menyadari ada faktor- faktor yang di sebabkan oleh plastik yang mereka buang bisa merusak lingkungan dari limbah plastik bahkan bisa juga merusak kesehatan. inilah akibat dari sampah plastik terhadap lingkungan yaitu racun-racun dari partikel plastik yang masuk ke dalam tanah akan berpotensi untuk membunuh hewan-hewan pengurai di dalam tanah, termasuk cacing, sampah plastik akan mengganggu jalur terserapnya air ke dalam tanah, sampah plastik yang susah diurai, mempunyai umur panjang, dan ringan akan semakin mempermudah untuk diterbangkan angin sehingga tidak menutup kemungkinan untuk mencemari lautan dan wilayah-wilayah lainnya secara bergantian.

Karena Limbah plastik inilah dan kurangnya pemahaman masyarakat sekitar tentang dampak limbah plastik terhadap lingkungan sehingga membuat penulis berfikir untuk membuat alat yang bisa mengubah limbah plastik dan bisa membuatnya menjadi sebuah kerajinan tangan dengan cara membuatkan sebuah cetakan sesuai dengan kerajinan tangan apa yang akan di buat agar tujuan tersebut bisa tercapai maka penulis merancang sebuah alat dimana alat ini bisa mengubah limbah plastik menjadi cair dan mencetaknya menjadi kerajinan tangan dimana prinsip kerja mesin ini yaitu menggunakan teori mesin screw dimana alat ini terdiri dari baja yang memiliki spiral atau helical fin yang tertancap pada shaft dan berputar dalam suatu saluran yang berbentuk "U" (through) tanpa menyentuhnya sehingga helical fin mendorong material ke trough. Shaft yang digerakan oleh motor gear. Conveyor di buat dengan ukuran panjang 8-12 ft yang dapat bersatu untuk memperoleh panjang tertentu. Diameternya bervariasi dari 3 sampai 24 inci. yang pada kesempatan ini penulis menggerakannya dengan dinamo starter motor yang memiliki fungsi untuk memutar roda penerus / roda gila sehinga poros engkol dapat berputar pada saat gerakan awal pada kendaraan, sehingga mesin bisa hidup. Sehingga dalam hal ini harus merangkai gear atau roda gigi dimana pada perhitungan putaran ini penulis menggunakan teori perhitungan torsi agar mengetahui putaran yang pada dinamo starter ini ter transfer ke screw dan menghantarkan limbah plastik ke jalur pemanas pada mesin vertical screw molding ini dimana pada kesempatan ini penulis menggunakan kontrol untuk menunjang fungsinya sebagai pengendali. Mulai dari pengaturan pemanasan pada dinding-dinding barrel, kecepatan injeksi, tekanan injeksi, waktu injeksi, waktu pencetakan serta beberapa fungsi lainnya.

Pada macam-macam jenis plastik memiliki titik leleh yang berbeda-beda disini penulis akan menjelaskan tentang macam-macam plastik dan pemanasannya berdasarkan derajat suhu celcius, PETE dengan $180^{\circ}-240^{\circ} \mathrm{C}$, HDPE dengan $200^{\circ}-280^{\circ} \mathrm{C}$, OTHER dengan $180^{\circ}-250^{\circ} \mathrm{C}$, LDPE dengan $160^{\circ}-240^{\circ} \mathrm{C}$, PS dengan $180^{\circ}-260^{\circ} \mathrm{C}$, PP dengan $200^{\circ}-300^{\circ} \mathrm{C}$, PVC dengan $160^{\circ}$ $280^{\circ} \mathrm{C}$ dengan pernyataan suhu pemanasnya dapat dinyatakan ketika suhu yang kita atur 
adalah paling maksimal maka plastik itu akan angsung mencair dan maka jika memakai minimum dari suhu maka plastik itu akan menair dengan lambat.

Dalam perancangan mesin ini penulis membuat gambaran menggunakan aplikas solidwork di mana aplikasi ini merupakan software yang digunakan untuk membuat desain produk dari yang sederhana sampai yang kompleks seperti roda gigi, cashing handphone, mesin mobil. software ini merupakan salah satu opsi diantara design software lainnya sebut saja catia, inventor, Autocad. Berdasarkan kajian maka penulis merancang mesin vertical screw molding untuk mengurangi limbah plastik yang sering di buang tidak pada tempatnya.

\section{METODE}

Didalam menentukan metode penelitian, harus dirancang terlebih dahulu seperti apa penelitian yang akan dilakukan. Fred N Kerlinger (dalam Landung R. Simatupang, 2000) mengungkapkan bahwa desain penelitian atau rancang bangun penelitian adalah rencana dan struktur penyelidikan yang disusun demikian rupa sehingga peneliti akan dapat memperoleh jawaban untuk pertanyaan-pertanyaan penelitiannya. Rencana itu merupakan suatu skema menyeluruh yang mencakup program peneliti.

Desain penelitian dibuat untuk menjadikan peneliti mampu menjawab pertanyaan penelitian dengan sevalid, se-obyektif, setepat dan sehemat mungkin. Rancangan penelitian adalah sebagai model pendekatan penelitian yang sekaligus juga merupakan rancangan analisis data. Disamping itu dengan adanya rancangan penelitian, penentuan sampel sudah diberi arah oleh rancangan penelitiannya. Desain penelitian yang digunakan dalam penelitian ini adalah penelitian dan pengembangan. Metode Penelitian dan Pengembangan (Research and Development) adalah metode penelitian yang digunakan untuk menghasilkan produk tertentu, dan menguji keefektifan produk tersebut. Menurut Sujadi (2003:164) Penelitian dan Pengembangan atau Research and Development (R\&D). adalah suatu proses atau langkahlangkah untuk mengembangkan suatu produk baru, atau menyempurnakan produk yang telah ada, yang dapat dipertanggung jawabkan.

Sugiyono (2015.407) adapun langkah pelaksanaan strategi penelitian dan pengembangan yang dilakukan untuk menghasilkan produk tertentu untuk menguji keefektifan produk yang dimaksud. Penelitian pengembangan yang dilakukan hanya sampai tahap revisi desain. Secara skematik langkah-langkah tersebut ditunjukkan pada gambar berikut.

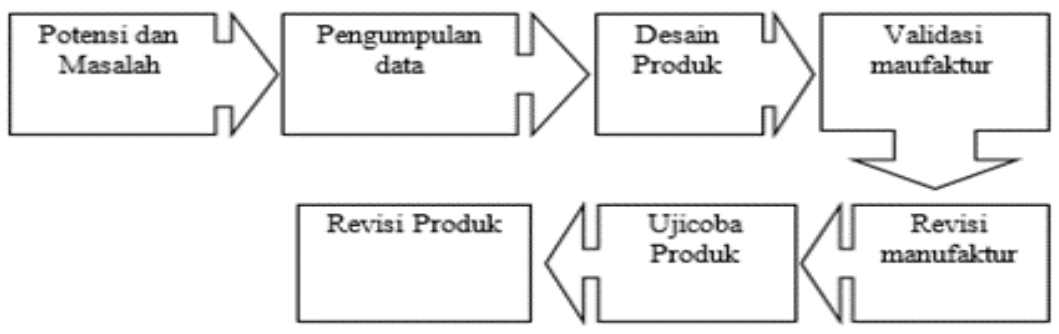

Gambar 1. Langkah-langkah penelitian $R$ \& D menurut sugiono

Sedangkan untuk memperjelas alur penelitian ini, adapun diagram alir (flowchart) dalam penelitian ini yang menyatakan urutan kegiatan yang dilakukan peneliti seperti pada gambar 2 . 


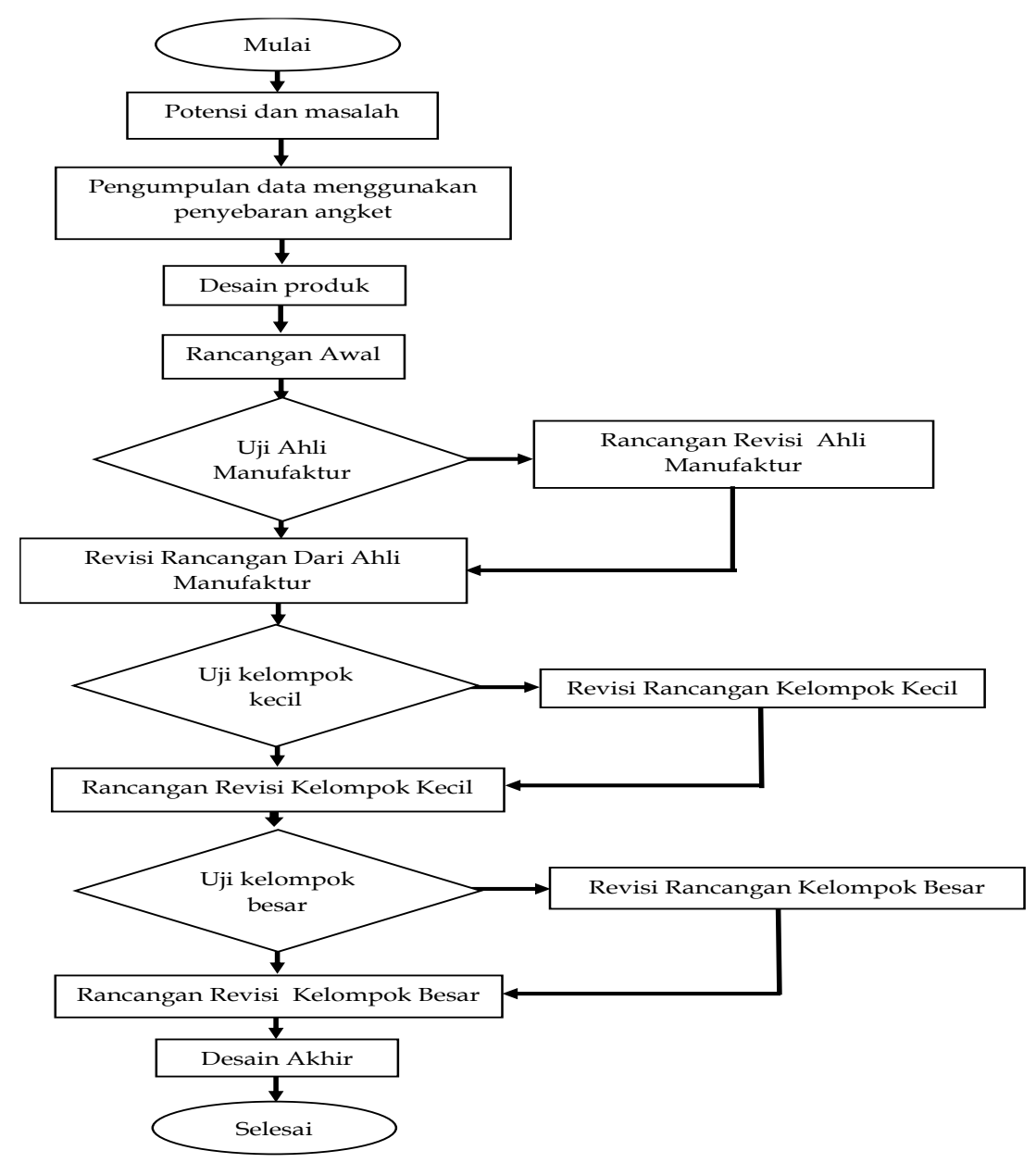

Gambar 2. Flowchart penelitian

Quality Function Deployment (QFD) merupakan suatu metode yang dipakai dalam tahap awal perancangan dan pengembangan produk dimana membuat rancangan kualitas dari suatu produk berdasarkan atas permintaan kualitas dari pemesanan (Customer) atau pasar (Market). QFD merupakan metode yang digunakan untuk mengantisipasi dan menentukan prioritas kebutuhan dan keinginan konsumen, serta menggabungkan kebutuhan dan keinginan konsumen tersebut dalam produk barang maupun jasa yang dihasilkan perusahaan.

QFD adalah suatu metode yang terstruktur didalam pengembangan produk yang memungkinkan tim pengembangan produk untuk menetapkan dengan jelas semua keinginan dan kebutuhan konsumen dan kemudian mengevaluasi masing-masing kemampuan produk atau servis yang ditawarkan secara sistematis untuk memenuhi kebutuhan konsumen [Cohen 95].

QFD merupakan suatu praktek untuk mengembangkan produk sebagai tanggapan terhadap kebutuhan pelanggan menjadi apa yang dihasilkan perusahaan dengan cara memberi prioritas dan juga merupakan praktek menuju perbaikan proses yang memungkinkan perusahaan melampoi harapan pelanggan [Ullman].

QFD adalah suatu alat dalam perencanaan yang dipergunakan untuk memenuhi keinginan pelanggan. [Besterfield.et.al,1995]. 
Jadi QFD merupakan alat bantu yang sangat tepat dalam suatu pengembangan produk dapat juga menghasilkan keteptaan dalam menganalisi keinginan dan kebutuhan cutemer sehingga bisa mengevaluasi masing-masing kemampun komponen dalam perancangan produk

\section{HASIL DAN PEMBAHASAN}

Penelitian ini di berdasarkan permasalah terhadap dampak limbah plastik yang ada maka membuat sebuah produk mesin yang didesaint menggunakan aplikasi solidwork 2014 untuk menghasilkan rancang bangun mesin vertical screw molding dengan penggerak dinamo starter sebagai pencair limbah plastik

Dari penyebaran angket rancang bangun mesin vertical screw molding dengan penggerak dinamo starter sebagai pencair limbah plastik di dapatkan hasil penyebaran angket permintan kebutuhan custemer (PKC) , uji manufaktur, uji kelompok kecil mendapatkan persentase 95.00\% lalu uji kelompk besar mendapat 90,32\%. Berdasarkan dari susunan house of quality (HOQ) yang dikembangan dalam rancang bangun mesnin vertical screw molding dengan penggerak dinamo starter sebagai pebcair limbah plastik di dapatkan hasil

Tabel 1. Hasil perhitungan dari house of quality (HOQ)

\begin{tabular}{lc}
\hline \multicolumn{1}{c}{ PKK } & $\begin{array}{c}\text { Hasil Bobot } \\
\text { PKK }(\%)\end{array}$ \\
\hline PKK 1: Dimensi 150x 30cm x 30cm & 25,4 \\
PKK 3: harga terjangkau & 24,07 \\
PKK 5: Band heater & 22,22 \\
PKK 2: Desain simpel & 14,8 \\
PKK 4: Body mesin menggunakan & 12,96 \\
pipa besi ukuran 2dim & \\
\hline
\end{tabular}

Dari hasil diatas didapakanlah rancangan mesin pencair limbah plastik dengan penggerak dinamo starter sebagai berikut

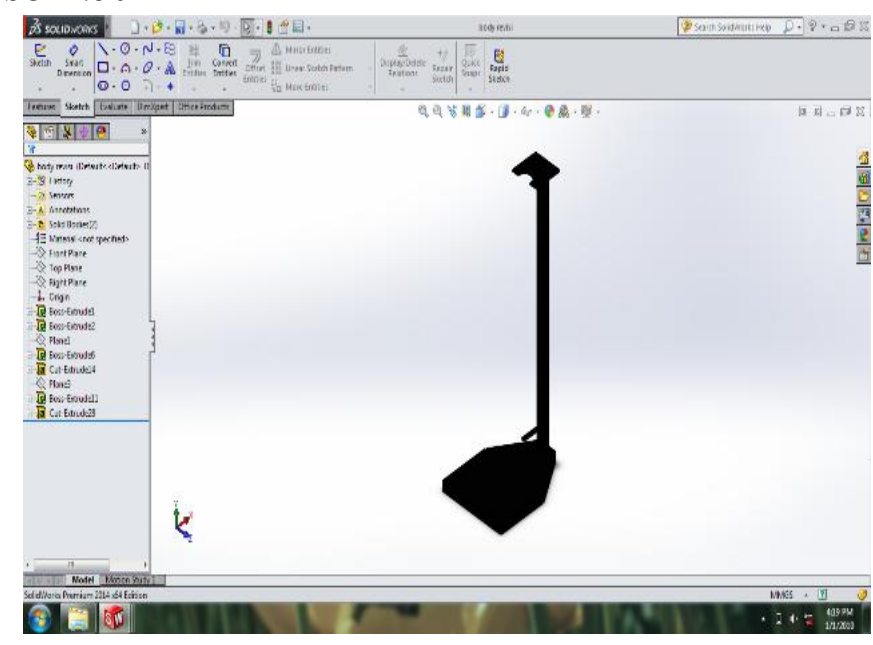

Gambar 3. Desain dan ukuran bodi mesin vertical screw molding 


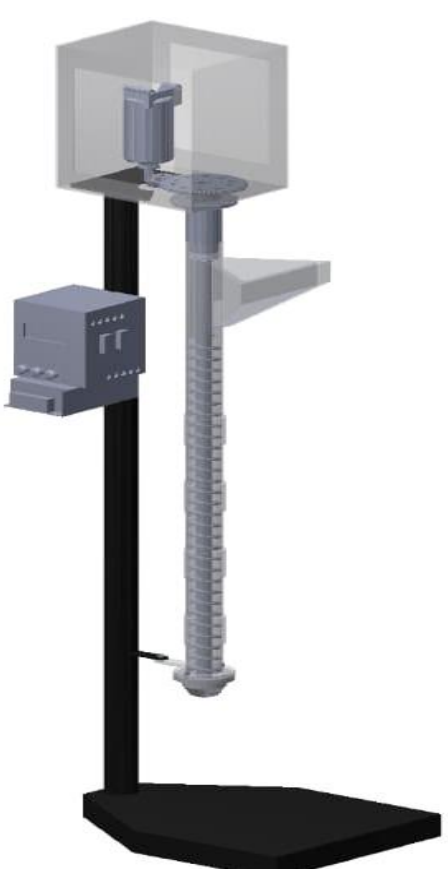

Gambar 4. tampilan rancangan mesin vertical screw molding

Tabel 2. Spesifikai Mesin Vertical screw molding

\begin{tabular}{cc}
\hline \multicolumn{1}{c}{ Nama alat } & Mesin vertical screw molding \\
\hline \multicolumn{1}{c}{ Fungsi alat } & Mesin Pencair limbah plastik \\
\hline Bentuk alat keseluruhan & Mengurangi limbah plastik \\
Dimensi : & \\
- Panjang & $30 \mathrm{~cm}$ \\
- Tinggi & $150 \mathrm{~cm}$ \\
- Lebar & $30 \mathrm{~cm}$ \\
\hline
\end{tabular}

Bahan kontruksi alat

- Bodi

Pipa besi ukuran 2 dim

Pipa kotak dan plat besi ukuran 0,6mm

- Alas mesin Pipa stenlis ukuran 2 dim

Siku $3 \times 3$ dan plat $0,6 \mathrm{~mm}$

- Tabung screw

- Rumah gear

Heater band (elemen pemanasnya)

Dinamo starter

Sepasang roda gigi

Control mesin

Berikut ini adalah proses manufaktur dalam pembuatan produk mesin vertical screw molding yang di dalamnya ada proses bubut, pengelasan, pemotongan bahan dan pembuatan kontrol mesin vertical screw molding. 


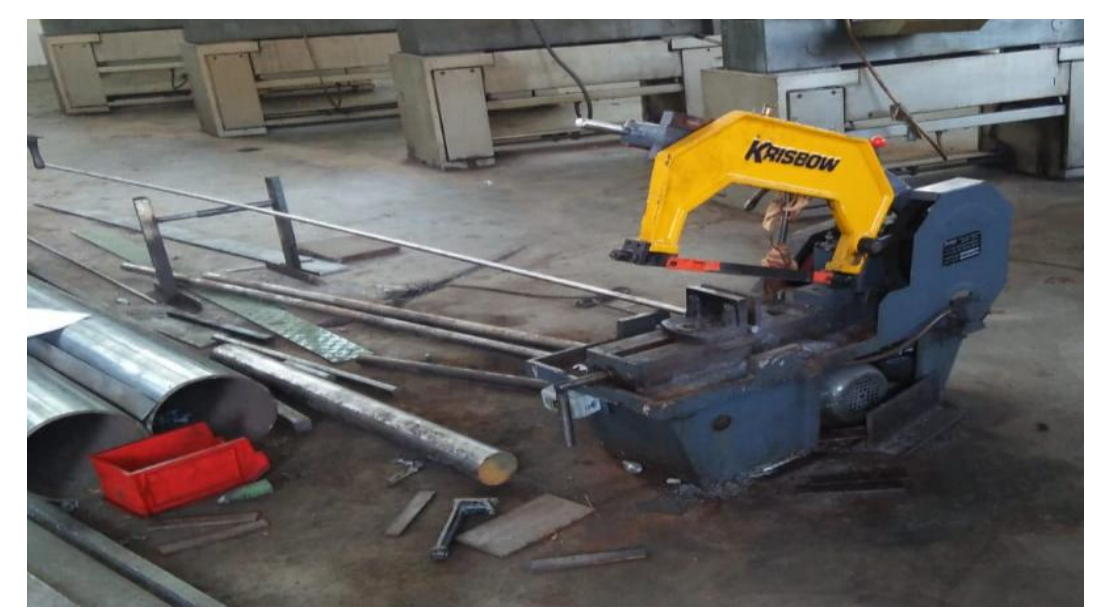

Gambar 5. Proses pemotongan bahan yang akan di pergunakan

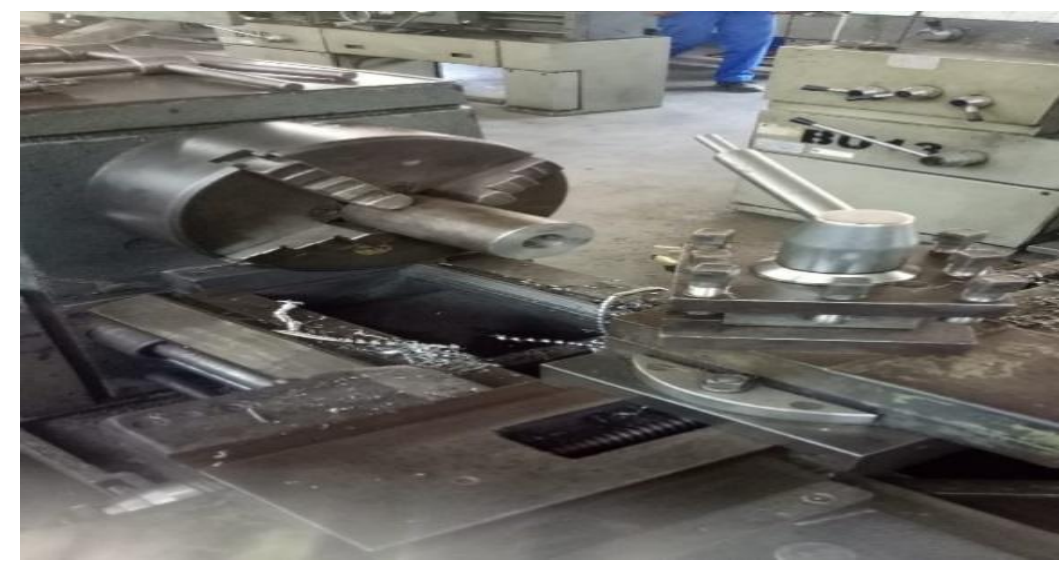

Gambar 6. Proses pembubutan komponen mesin vertical screw molding

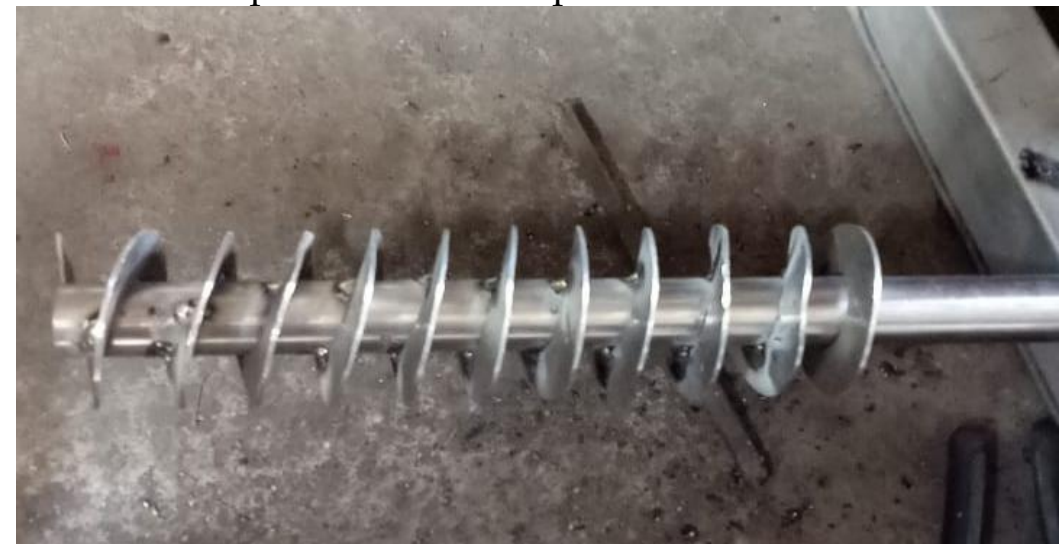

Gambar 7. Proses pengelasan komponen mesin vertical screw molding 


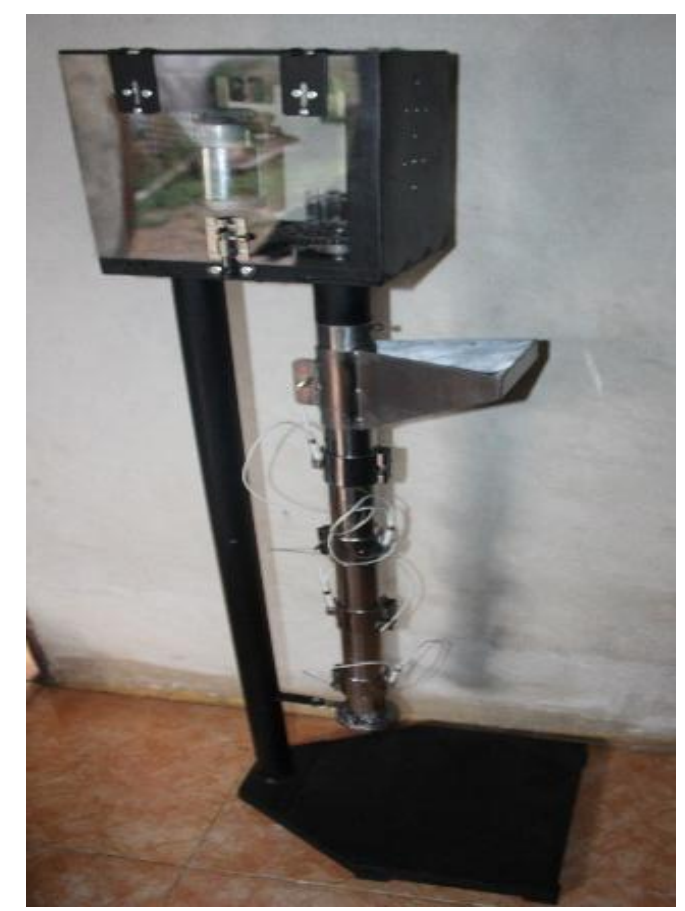

Gambar 8. Proses perakitan mesin vertical screw molding setengah selesai

Setelah proses pada gambar 7 sampai 10 maka di lanjukan dengan perancangan control mesin vertical screw molding dan pemasangan control pada mesin vertical screw molding.

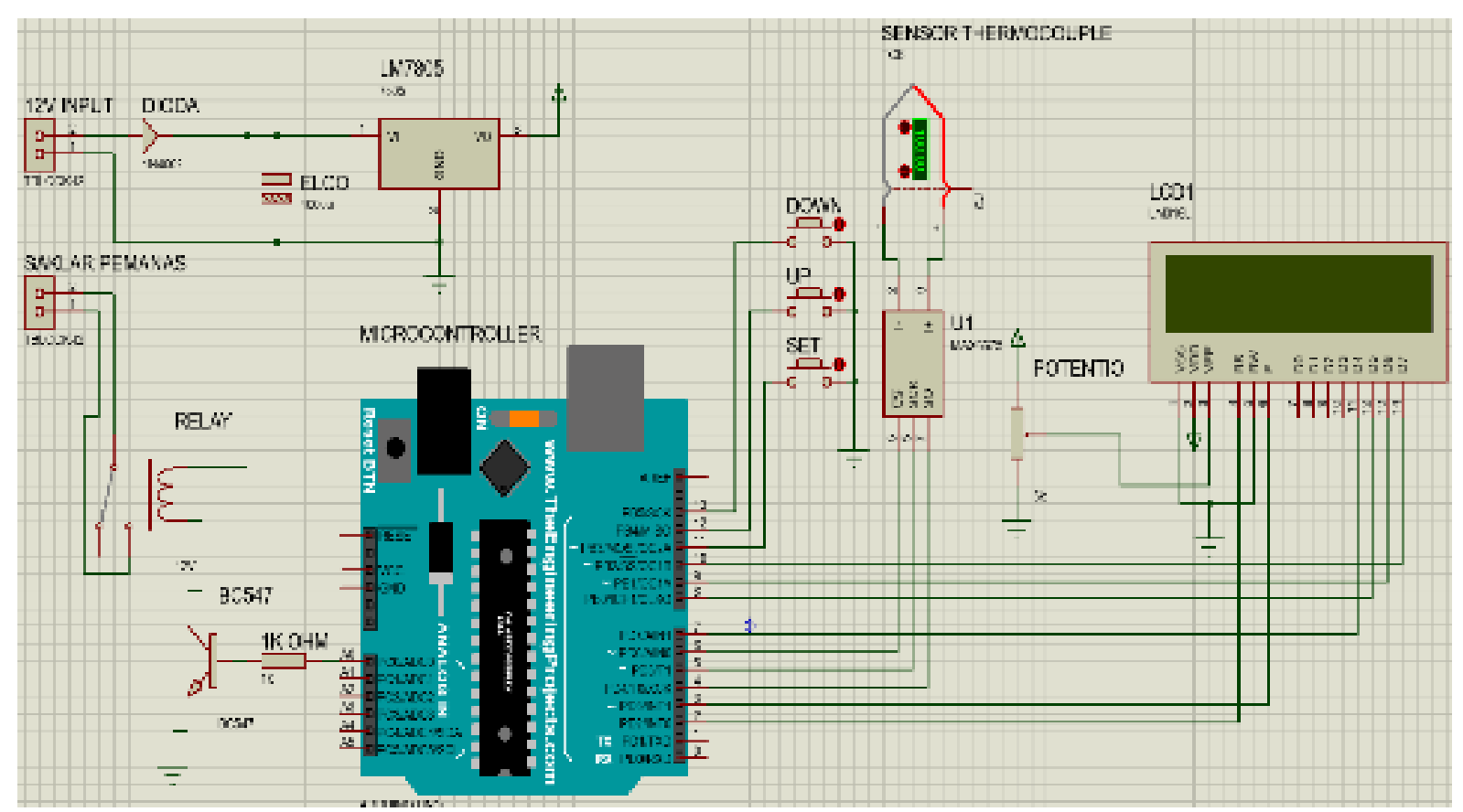

Gambar 9. Rancangan control mesin vertical screw molding 


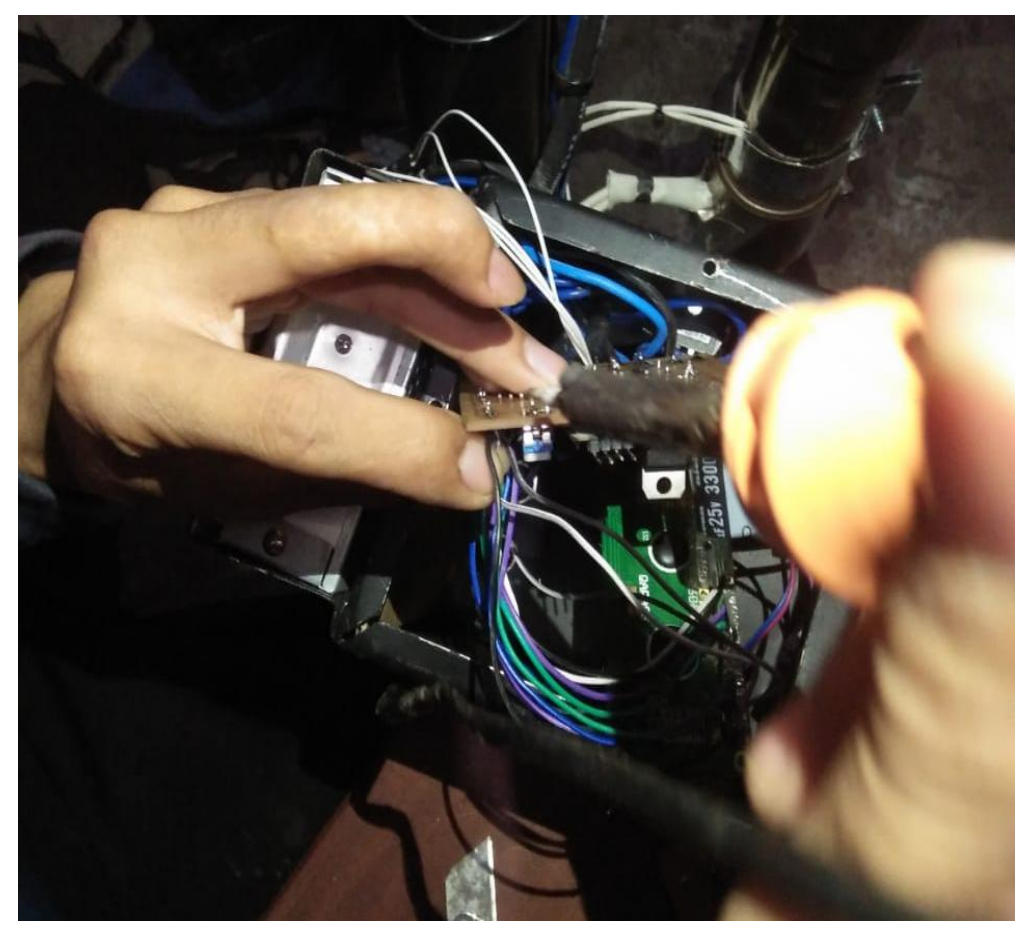

Gambar 10. Pemasangan komponen control mesin vertical screw molding

Ketika semua proses dari pemotongan bahan, pembubutan, pengelasan, perakitan, perencangan dan perakitan control maka berikut ini adalah gambar ketika mesin vertical screw molding dengan penggerak dinamo stater sebagai pencair limbah plastik sudah selesai

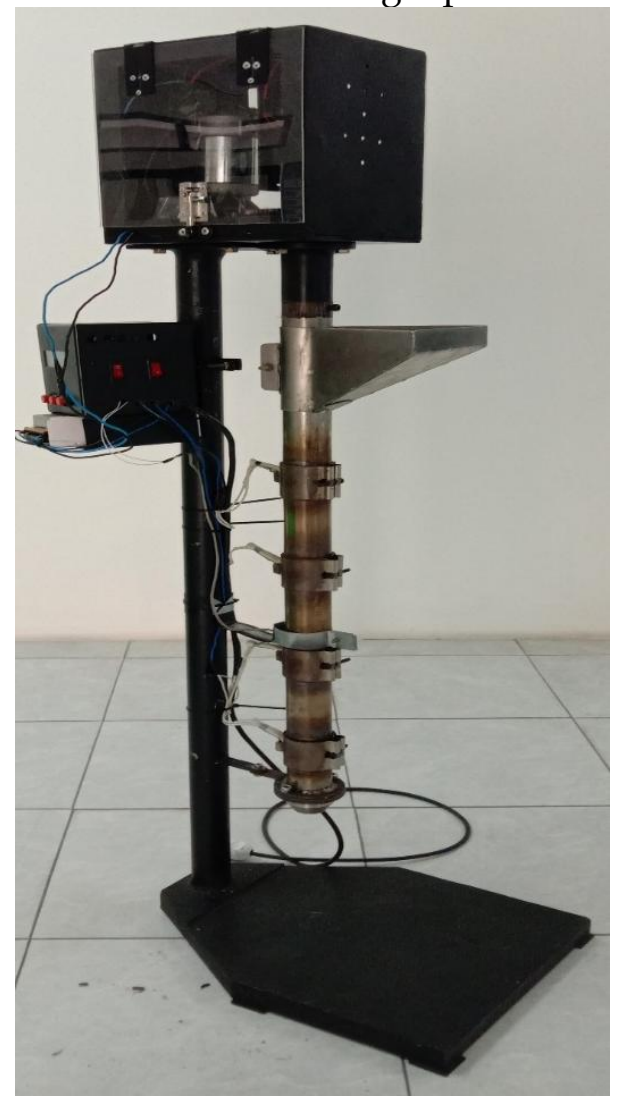

Gambar 11. Produk mesin vertical screw molding 


\section{KESIMPULAN DAN SARAN}

Berikut ini adalah beberapa kesimpulan dari rancang bangun mesin vertical screw molding dengan penggerak dinamo starter sebagai pencair limbah plastik adalah sebagai berikut :

Rancang bangun mesin vertical screw molding dibuat dengan dimensi ukuran yaitu $30 \mathrm{~cm} x$ $30 \mathrm{~cm} \times 150 \mathrm{~cm}$ yang terdiri dari beberapa komponen yang mendukung kinerja alat serta dirancang dengan penggerak diamo starter sebagai pencair limbah plastik ini mendapakan data hasil penyebaran kuisioner pada ahli manufaktur dan mendapatkan hasil sangat layak dilanjutkan. penulis menyebar kuisioner pada kelompok kecil yang mendapatkan persentase skor sebesar 95,00\% jadi dapat disimpulkan dari hasil penyebaran kuisioner tersebut sangat layak untuk di lanjutkan, dan hasil data pada kelompok besar pada 9 orang masyarakat dan 16 orang mahasiswa mendapatkan juga persentase skor sebesar 90,32\% dapat dinyatakan sangat layak.

Adapun saran yang yang penulis sampaikan agar menyepurnakan dan melangkapi penelitian ini yaitu :

Dapat dilakukannya uji coba dan pertimbangan komponen-komponen pada mesin ini agar bisa beroprasi dengan maksimal. Kemudian dapat dilakukannya pertimbangan mengenai ketahanan dinamo DC dari pada dinamo AC jika akan digunakan dilapangan. Serta hasil cairan plastik itu langsung dibuatkan cetakan khusus untuk mesin vertical screw molding.

\section{DAFTAR RUJUKAN}

Agus (2003). Pemeliharaan kelistrikan pada sepeda motor. halaman: 65 Diakses Pada 18 April 2017.

Devi, K .H. (2011). Simbol untuk menunjang system informasi desain kemasan makanan dan minuman plastik. halaman:6 Diakses Pada Tanggal 14 Juli 2018.

Dikshon, K. (2015). Pengertian relay. halaman: 1 Diakses pada tanggal 13 juli 2018.

Herman, D. S. (2007). Elekronika Teori dan Penerapan. Jawa Timur.

Imam, M. (2005). Sifat dan karakteristik material plastik dan bahan aditif. Semarang

Eanita, Q. Q. (2013). Gear adalah pengertian dan definisi roda gigi. Tersedia Pada http: kamusq.com. diaskes pada tanggal 18 April 2017.

Lutfiana, A (2015). Mikrokontroller arduino nano. Diaskes Pada Tanggal 13 Juli 2018.

Muhamad, S. (2017). Racaang bangun plastic injection moulding pada pemamfaatan limbah plastik untuk gagang pisau. halaman: 35 diaskes pada tanggal 20 Februari 2020.

Olivian, M. S., dkk. (2015). Perancangan alat ukur krcepatan kendaraan menggunakan ATMEGA 16. Manado: halaman 4.

Rochman, R., dkk. (2018). Pengaruh perlakuan panas terhadap kekerasan dan struktur mikro baja AISI 310 S. halaman:3 diaskes pada tanggal 15 juli 2018 
Samujizaki, (2016). Dinamo starter dan fungsinya. tersedia pada utomotif123.blogspot.com diaskes pada tanggal 18 April 2019

Sugiono. (2010). Metoda penelitian pendidikan (pendekatan kualitatif kuantitatif dan RED. Bandung : Alfabert Halaman: 312

Wildann. (2019). Dampak sampah plastik terhadap lingkungan. tersedia pada http:www.kompasiana.com diaskes tanggal 1 Januari 2020 